\title{
E-PARTISIPASI VIRTUAL DALAM SELAMATKAN LINGKUNGAN DI ERA DIGITAL
}

\author{
Kheyene Molekandella Boer
}

Ilmu Komunikasi Universitas Mulawarman

Jl. Kuaro Kampus Gunung Kelua. Gedung Dekanat Fisipo Universitas Mulawarwan Samarinda Kalimantan Timur

e-mail: delex_boer@yahoo.com

\begin{abstract}
Issues about the environment often become the spotlight of the world, ranging from technological developments to a million environmental problems that never end. Now environmental issues are touched by the rapid development of digital technology. This makes a big change for the world of the environment. Ranging from digital conversations to top level or government decisionmaking to making environmental policies, all references are taken from community activities and participation that often voice their opinions on social media. Communication technology in the context of the environment that is most widely seen is the phenomenon of online petitions or known as "change.id". a site that offers space to discuss anything including environmental issues. The power of online petitions that move quickly by collecting votes through online signatures is able to stop the government's steps to dismantle Sophie's ship in Aceh. The reason is to save ecosystems such as long-developed coral reefs around the sophie ship that sank many years ago. E-participation as a form of digital democracy. Where the public is not obliged to appear physically in front of the government, through interactivity built in online media makes every active person involved without being limited by distance, space and time. Of course, with the concept of e-participation it is hoped that environmental issues can be controlled not only by the government but by the public. Because one indicator of the development of a country's progress is one of which is seen from the level of people's participation.
\end{abstract}

Keyword; e-participation, environmental communication, digital democracy 


\begin{abstract}
Abstrak
Isu tentang lingkungan hidup kerap menjadi sorotan dunia, mulai dari perkembanganteknologihinggasejuta permasalahanlingkunganyangtakkunjung usai. Kini isu lingkungan hidup terjamah pula oleh pesatnya perkembangan teknologi digital. Hal ini menjadikan perubahan besar bagi dunia lingkungan hidup. Mulai dari perbincangan digital hingga pengambilan keputusan top level atau pemerintah hingga membuat kebijakan tentang lingkungan, seluruh refrensinya diambil dari aktivitas dan partisipasi masyarakat yang kerap menyuarakan opini mereka di media sosial. Teknologi komunikasi dalam konteks lingkungan hidup yang paling santer terlihat adalah fenomena petisi online atau yang dikenal dengan "change.id". sebuah situs yang menawarkan ruang untuk berdiskusi tentang apapun termasuk isu lingkungan hidup. Kekuatan petisi online yang bergerak cepat dengan mengumpulkan suara melalui tanda tangan online mampu menghentikan langkah pemerintah untuk membongkar kapal Sophie yang berada di Aceh. Alasanya adalah menyelamatkan ekosisitem seperti terumbu karang yang sudah lama berkembang di sekitar kapal sophie yang karam puluhan tahun lalu. E-partisipasi sebagai wujud demokrasi digital. Dimana publik tak wajib menampakan fisiknya di depan pemerintah, melalui interaktivitas yang dibangun di media online menjadikan setiap orang aktif terlibat tanpa dibatasi oleh jarak, ruang dan waktu. Tentunya dengan adanya konsep e-partisipasi diharapkan isu lingkungan dapat dikontrol bukan hanya oleh pemerintah tetapi oleh publik. Karena salah satu indikator perkembangan kemajuan sebuah negara salah satunya adalah dilihat dari tingkar partisipasi masyarakatnya.
\end{abstract}

Keyword; e-partisipasi, komunikasi lingkungan, demokrasi digital

\section{A. PENDAHULUAN}

Demokrasiatau kebebasan yang benarbenar bebas adalah konsep yang akhirnya kini terwujud dalam bentuk virtual. Tidak hanya elite politik yang berteriak menggaung-gaungkan demokrasi, semua sektor kehidupan manusia menjadikan konsep demokrasi sebagai landasan utama dalam berkomunikasi. Di Indonesia sendiri kebebasan berpendapat turut terlihat seiring terjadinya revolusi komunikasi yang dihadirkan internet. Publik kini kerap kritis berpendapat melalui saluran internet, mulai mengkritik kebijakan pemerintah, politik ekonomi, social hingga lingkungan. Tulisan ini akan membahas sejauh apa gerakan media online yaitu komunitas virtual dalam menggerakan aksis social untuk menyelamatkan lingkungan.

Faktanya kekayaan alam tidak luput dari permasalahan ego manusia yang merusak lingkungan dengan orientasi keuntungan. Diharapkan, hal ini tidak berlangsung lama, terwujud seiring pesatnya teknologi banyak suara positif yang singgah memanfaatkan teknologi untuk menyampaikan aspirasi mereka terhadap isu-isu lingkungan. Isu lingkungan kini kian santer terdengar, pesatnya revolusi teknologi menjadikan kita seperti berlomba - lomba melakukan sesuatu hal melalui fasilitas teknologi yang semakin mudah dijangkau. Lingkungan sebagai tempat/wadah masyarakat dimuka ini 
tinggal menjadi salah satu isu sentral yang tak lepas terangkat pula oleh keberadaan teknologi.

Internet menjadi salah satu cara untuk menyerukan aksi-aksi kepedulian terhadap lingkungan, seperti penyelamatan satwa yang hampir punah. Petisi ada;ah cara paling popular hingga saat ini yang masih dipergunakan oleh publik. Caranya yang sangat mudah menjadikan situs Change. id digemari oleh jutaan orang yang ingin berbuat sesuatu untuk lingkunganya. Tentunya keterlibatan ini menjadi cerminan demokrasi kita di era digital. Puluhan petisi dan jutaan tanda tangan virtual tentang lingkungan mampu menembus kebijakan elite atas dengan cepat. Sebuah gerakan demokrasi yang luar biasa!

\section{B. HASIL DAN PEMBAHASAN}

\section{Isu Lingkungan di Change.id}

Salah satu platform change.or.id adalah salah satu pelopor platform yang banyak digunakan masyarakat untuk menyerukan aspirasi mereka. Situs ini berasal dari Amerika serikat tahun 2007 dan memperluas bisnisnya salah satunya masuk ke Indonesia di tahun 2012. Cara kerja petisi ini yakni cukup membubuhkan tanda tangan virtual sebagai bukti keterlibatan dan kontribusi yang baik pada sebuah isu yang sedang digaungkan.

Lindner \& Riehm (2011) mengatakan petisi sebagai permintaan otoritas public, biasanya institusi pemerintahan atau parlemen. Petisi online meningkatkan proses demokrasi, menghubungkan warga Negara dengan pemerintahan dan memfasilitasi keterlibatan warga Negara (Panagiotopoulos * AkDebei,2010).
Change.id sendiri telah menggemakan banyak isu-isu mulai dari politik, ketidakadilanhukumhinggaisulingkungan. Direktur Change.org Indonesia Arif Aziz mengatakan jumlah warga net ditahun 2017 sebanyak 117 orang dan ditahun 2018 meningkat dalam menyuarakan isu lingkungan yaitu sebanyak 17 kali lipat atau 2,1 juta orang .

Petisi juga berhasil mendapatkan tujuanya seperti menuntut pemerintah memberikan hukuman kepada pembakar hutan, mendukung 2 akademisi IPB Bambang Hero dan Basuki Wasis yang digugat memberikan keterangan sebagai ahli dikasus pembakaran hutan dan korupsi.

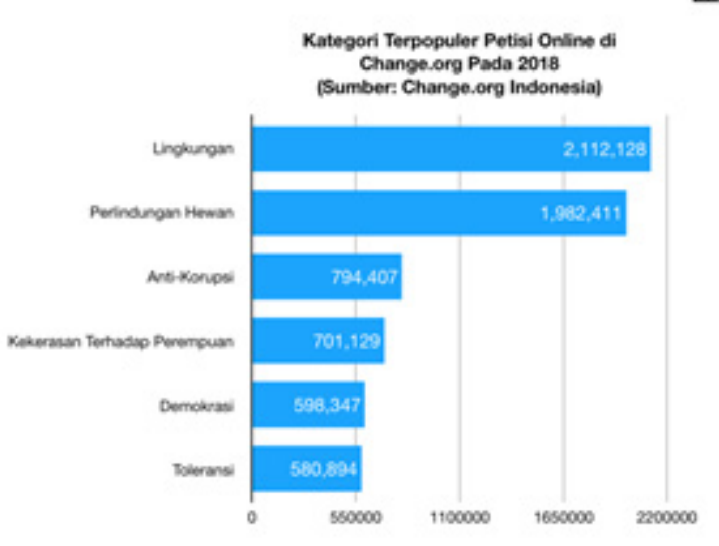

Gambar 1.

Kategori Terpopuler Petisi Online di Change.org Pada 2018 (Sumber : Change.org)

Dari kuantitas / jumlah tanda-tangan, terdapat enam kategori yang menjadi perhatian masyarakat pada 2018. Topik lingkungan memimpin posisi pertama $(2,11$ juta tanda tangan), disusul perlindungan hewan (1,98 juta), anti-korupsi (794 ribu), kekerasan terhadap perempuan (701 ribu), demokrasi (598 ribu), dan toleransi (580 ribu). Topik-topik tersebut memang menjadi 
perhatian warganet dalam beberapa tahun terakhir dengan sedikit pergeseran. Pada 2017 topik terpopuler adalah hak asasi manusia(HAM) sementara pada 2016adalah toleransi. https://www.voaindonesia. com/a/ini-6-topik-terpopuler-petisionline-pada-2018/4710847.html.

Tanggal 6 Agustus 2018 WWF Indonesia mengapresiasi tindakan cepat Change.org dan pembuat petisi "Stop Tipu Daya atas Nnama Konservasi" atas perunaham funhsi kawasan konservasi Taman Nasional Komodo dan ditujukan kepda kementrian lingkungan hidup dan kehutanan (KLHK) dan balai Komodo. Publik menuntut WWF untuk melakukan pengelolaan kawasan konservasi laut, perikanan berkelanjutan dan pariwisata yang bertanggungjawab.

Lingkungan merupakan salah satu isu pokok yang kerap diwacanakan dalam berbagai kesempatan,salah satunya adalah banyaknya aksi kampanye social yang dilakukan oeleh pemerintah ataupun pihak swasta. Menurut Kotler kampanye harus memilii goals/tujuan yang berujung pada perubahan social, yaitu perubahan sikap dan perilaku masyarakat. Kontler dan Amstrong merumuskan dua gerakan utama yang dapat mendukung perubahan social itu adalah environmentalism, yaitu gerakan terorganisir yang melibatkan pemerintah dan masyarakat untuk melindungi dan meningkatkan lingkungan hidup masyarakat saat ini dan masa datang. Gerakan ini bukan gerakan melawan pemasaran dan konsumsi tetapi lebih kepada menuntut measyarakat dan produsen untuk lebih menghargai lingkungan (Kotler danAmstrong,2012:583)

\section{Save Sophie, Gagalkan Pembongkaran} Kapal Karam demi Menyelamatkan Ekosistem

Salah satu petisi yang meraih kemenangan adalah petisi tentang kapal karam dengan hastag \#SaveSophie.Petisi yang dibuat oleh aktivis Aceh Nurjannah Husein ditahun 2014. Petisi yang ditujukan kepada kementrian kelautan dan perikanan RI yaitu Susi Pudjiastuti meraih pendukung sebanyak 15.021 pendukung. Sophie adalah kapal mesin uap asal jerman yang karam di perairan Sabang, Aceh pada perang dunia ke II tahun 1920.

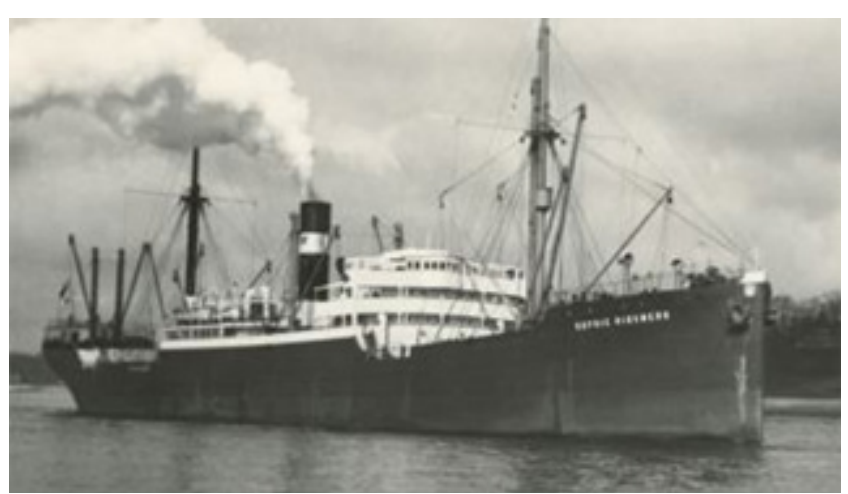

Gambar 2.

Kapal Sophie saat Perang Dunia ke II (Sumber : www.mongabay.co.id)

Nurjannah Husein menilai pembongkaran kapal sophie, berdampak buruk bagi keanekaragaman hayati, pariwisata, penghidupan nelayan dan pengetahuan sejarah.Sophie kini dijadikan tempat hidup tumbuhan laut bahkan wisata selam yang sangat menarik di aceh. Hingga munculah rencana pemerintah kota membuat bunker minyak bawah laut yang mengharuskan salah satu syaratnya membongkar isi dari kapal Sophie yang sudah tertidur selama 74 tahun tersebut. 


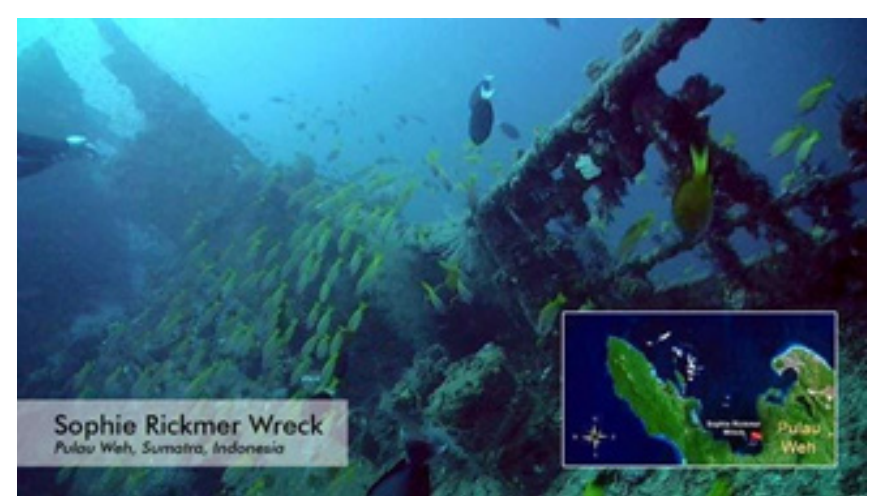

Gambar 3. Suasana Kapal Sophie yang telah karam tetap elok dijadikan ekosistem bagi fauna dan flora laut

Menurut masyarakat kapalSophie kini menjadi identitas dari aceh sebagai wisata selam ternama, dimana ketika menyelam kita bisa menemukan wisata sejarah yang sangat luar biasa didalamnya, bukan hanya itu kita juga dapat menyaksikan keindahan tumbuhan laut dan hewan laut hidup emnghiasi bangkai kapal sophie. Hal tersebut dianggap sebagai identitas wisata aceh, sumber sejarah yang bisa diceritakan ke anak cucu kita. Lantas banyak pro dan kontra haruskan bisnis bunker tersebut ditukar dengan mengirbangkan kapal sophie?

Hingga akhirnya walikota Aceh membatalkan rencana tersebut dan tidak akan mengangkat kapal itu, walikota juga mengakui bahwa bangkai kapal telah menjadi ekosistem yang menarik bagi wisata dan sejarah dunia.

Gerakan sosial sendiri harus dipahami sebagai sebuah : (1) kolektivitas orang yang bertindak bersama; (2) tujuan tindakan bersamanya adalah perubahan tertentu dalam masyarakat dengan cara yang sama; (3) kolektivitas relatif tersebar namun lebih rendah derajatnya daripada organisasi formal; (4) tindakannya mempunyai derajat spontanitas relatif tinggi namun tak terlembaga dan bentuknya tak konvensional. Jadi gerakan sosial adalah tindakan kolektif yang diorganisir secara longgar, tanpa cara terlembaga untuk menghasilkan perubahan dalam sebuah masyarakat (Octavianti, 2014: 46).

\section{Komunitas Virtual}

Media social hadir membawa nilainilai baru di tengah penggunanya, tidak hanya dimanfaatkan dalam menceritakan diri (self disclosure), tetapi juga meningkat menjadi medium aspirasi warga secara online (Jordan, 1999; Saco,2002; Wilhelm, 2000)

Mediamorfosis yang dipopulerkan oleh Fidller di tahun 1990-an menggambarkan perubahan media lama menajdi media baru. Dua prinsip penting dari kaum technorealism, "technologies are not neutral" dan "the internet is revolutionary not Utopian" (Wilhelm,2000:32) menjelaskan bahwa walaupun dunia telah diserbu oleh teknologi namun tidak membutuhkan proses panjang dalam mengubah pola komunikasi public yang telah ada sebelumnya.

Revolusi Komunikasi menghadirkan produk baru bernama teknologi. Teknologi raksasa yang semakin kuat pesonanya dalam mendominasi arus komunikasi saat ini. Lambat laun aspek apapun turut diwarnai oleh keberadaan teknologi internet, salah satunya menyoal isu lingkungan hidup yang menjadi potensi Indonesia turut ada di bicarakan di setiap ruang-ruang virtual.

Virtual communities are social aggregations that emerge from the Net ehen 
enough people carry on those public discussion long enough with sufficient human feeling, to form webs of personal relationships in cyberspace [Howard Rheinghold,1993:5]

Portal adalah istilah yang ada dalam internet, sering diartikan sebagai gerbang atau pintu masuk ke suatu ruang virtual yang berbeda-beda. Portal merupakan pengalaman pertama atau "first hand experience" dari satu titik yang akan menuju titik-titik lainnya (Nasrullah,2014:24). Karaketristik media online adalah interkoneksi yang kuat, menghubungkan person by person dimana-pun berada, membanjiri individu dengan informasi hingga mampu menggerakan aksi secara virtual.

Petisi online sebagai ruang public untuk mewacanakan isu-isu lingkungan, atau yang biasa disebut Poster (1995) dengan virtual sphare atau ruang virtual. Komunitas virtual adalah sebuah bentuk hubungan yang diciptakan internet, dimana para anggotanya akan berinteraksi dalam waktu yang cukup lama, menorehkan ide dan gagasan, berdiskusi. (www.tirto.id/ petisi-isu-lingkungan paling populer di Change.Oord sepanjang 2018/by Riyan etiawan 20 desember 2018.

Dalam internet, posisi khalayak menjadi dua yaitu konsumen dan produsen. Di Internet khalayak bisa menjadi keduanya, sebagai konsumen sekaligus produsen, dikenal sebagai istilah prosumer (Casearo,2011;403) atau produsage (Bruns,2010). Seperti dalam petisi online di Change.id setiap orang bisa membaca isu lingkungan yang sedang hangat ia memposisika diiri sebagai konsumen, dan saat ia memutuskan mempublikasi atau menyebarluaskan isu lingkungan tersebut kepada anggota lainya maka ia sekaligus berganti peran menjadi seorang produsen pesan.

\section{E-Partisipasi}

Perkembangan zaman menjadikan demokrasi tidak harus terlibat secara fisik, partisipasi terus menyesuaikan diri dengan canggihnya teknologi. Begitu penting partisipasi, karena merupakan sebuah agenda penting untuk perubahan suatu Negara, keterlibatan warga Negara menjadi salah satu barometer kemajuan suatu bangsa. Macintosh (2004:3 dalam Moreno dan Traverso,2010) mengklasifikasikan jenis prakarsa pemerintah yang terkait dengan e-partisipasi : (1) tipe pertama, e-enabling yaitu berfokus pada penyampaian informs yang mudah dipahami kepada khalayak seluas mungkin; (2) tipe kedua, e-engaging, yaitu penyampaian informasi bersifat lebih spesifik misalnya mengenai topic poliyik dan bersifat dari atas ke bawah (Top-Down); (3) E-empowering, yaitu warga terlibat aktif dalam penyampaian gagasan (bottomup) yang kemudian menjadikan mereka produsen daripada sekedar konsumen dalam sebuah kebijakan.

Tujuandariadanyae-partisipasiadalah (Macintosh, 2004 dalam Parlak dan Sobaci, 2010) yakni : (1) memperluas jangkauan untuk meningkatkan partisipasi warga; (2) penggunaan teknologi untuk memfasilitasi teknik komunikasi yang berbeda-beda di masyarakat; dan (3) menyediakan informasi yang relevan dan lebih mudah dipahami warga agar mereka bersedia terlibat lebih mendalam (deliberatif).

Parlak dan Sobaci (2010 : 78) partisipasi memberikan keuntungan seperti

ISSN : 2085-3521, E-ISSN : 2548-9054 
meningkatkan kebahagiaan, memberikan kepuasan, perasaan yang dilibatkan, serta adanya omitmen terhadap masyarakat yang lebih besar.

Petisi Change.id adalah wujud dari e-partisipasi dalam rangka melakukan control terhadap ancaman yang sedang dan akan menimpa kondisi lingkungan di Indonesia. Aktivitas di ruang cyber dalam petisi tersebut terbilang sederhana hanya dengan membubuhkan tanda tangan telah menjadi bentuk e-partisipasi itu sendiri, sehingga diharapkan kondisi ini mampu menggerakan pola komunikasi bawah ke atas (down-top).

Salah satu petisi yang beredar agustus 2018 "Stop Tipu Daya atas nama Konservasi” dibuat oleh WWF-Indonesia yang telah mendapatkan dukungan lebih dari 12.000 orang (senin,6 agustus 2018, pukul 17.00) dinilai tidak tepat sasaran sehingga pihak WWF meminta Change.Id dan pihak pembuat petisi untuk meralat. Petisi dengan \#SaveKomodo berawal dari keluarnya surat keputusan badan penanaman modal (BPM) No 7/1/IUPSWA/PMDN/2015 tanggal 17 Desember 2015 tentang pemberian izin usaha sarana wisata alam pada zona pemanfaatan TN komodo seluas 22,1 hektar dan SK kepala balai TN komodo No 169/T.17/TU/KSA/04/2018 tentang pengesahan Rencana Tahunan (RKT) oengusahaan pariwisata alam tahap III tahun 2018 atas nama PT.Segar Komodo Lestari.(www.wwf.or.id) WWF merasa bukan pihak berwenang yang memiliki kapasitas menghentikan kegiatan tersebut, melainkan kementrian LHK cq. Ditjen KSDAE cq Kepala Balai Taman Nasional Komodo.

\section{Ruang Publik}

Ruang publik menurut Habermas dalam Budi Hardiman (2010:189) memiliki tiga cirri utama yaitu (1) para aktornya bukan berasal dari birokrasi Negara ataupun dari kalangan bisnis, melainkan 'orangorang privat' yaitu warga negara biasa; (2) terjadi suatu proses pemberdayaan diantara mereka, yaitu pertimbangan-pertimbangan rasional tanpa rasa takut dinyatakan secara public dan dilandasi oleh keprihatinan terhadap persoalan yang merugikan public; dan (3) ruang public itu sendiri menjadi mediasi antara isu-isu privat para individu didalam kehidupan keluarga, bisnis dan social.

Karakteristik khalayak di internet terbagi menjadi (Dahlberg,2001) dalam nasrullah, 67 yakni : (1) autonomy from state and economic power; forum haruslah bebas dari intervensi Negara atau kekuatan ekonomi mana-pun; (2) exchange and critique of criticizable moral-practical validity claims ; terdapat pertukaran dan perdebatan yang berlandaskan moral untuk melihat suatu peristiwa dibandingkan dengan dogma yang memaksa.Setiap anggota berada dalam posisi sama siap menyampaikan kritik dan siap pula dikritik; (3) reflexivity; setiap anggota forum hendaknya kritis dalam mempertimbangkan nilai-nilai budaya, asumsi yang terjadi di tengah realitas sosial; (4) ideal role taking ; setiap anggota harus memiliki integritas dalam memahami argument yang berkembang, meski datang dengan perspektif yang berbeda; (5) sincerity ; anggota melandasi diriya dengan niat tulus, termasuk dalam hal keinginan, kebutuhan hingga tujuan yang tersembunyi untuk menemukan solusi terhadap suatu 
masalah bukan untuk kepentingan pribadi; dan (6) discursive inclusion and equality; cyber forum beroperasi dengan menghormati setiap anggotanya dengan memberikan kesempatan untuk mempertanyakan dan termasuk menyanggah suatu isi. Karena tidak menutup kemungkinan ada yang ingin mendominasi/ingin didengar serta memaksakan argument.

\section{SIMPULAN}

Demokrasi digital kini menjadi penting untuk terus memberikan kontribusi terhadap pembangunan disuatu daerah. Menjadi sebuah ruang bebas hmambatan untuk terus menyuarakan ide, gagasan dengan satu tujuan yakni kemajuan dan kepentingan bersama. Terutama isu lingkungan hidup yang selalu kalah dengan isu politik. Kini, isu lingkungan kian santer terdengar permasalamhman dmanm aksi cepat tanggapnya. Semuanya karena perkembangan teknologi yang menjadikan semua element kehidupan manusia semakin mudah.

\section{DAFTAR PUSTAKA}

Casearo, Giovanni. (2011). From the "Work of Consumption" to the "Work of Prosumer". Dalam wasko. Jane, Murdock, Graham and Sousa, Helena (ed.). The Handbook of Political Economy of Comunications. West Sussex:Wiley-Blackwell.

Hardiman,Budi. (2010). Komersialisasi Ruang Publik Menurut Hannah Arendt dan Jurgen Habermas : Ruang Publik, Yogyakarta: kanisius

Octavianti, Meria. (2014). Alur Pesan Kampanye Gerakan Cikapundung Bersih Dalam Meningkatkan Kesadaran Kebersihan Lingkungan. Jurnal Komunikasi Universitas Tarumanagara, Tahun VI/02/2014

Kotler, Philip \& Gary Armstrong. (2012). Principles of Marketing 14th ed. New Jersey: Pearson Education

Octavianti, Meria. (2014). Alur Pesan Kampanye Gerakan Cikapundung Bersih Dalam Meningkatkan Kesadaran Kebersihan Lingkungan. Jurnal Komunikasi Universitas Tarumanagara, Tahun VI/02/2014

Jordan,T. (1999). Cyberpower, The Culture and Politics of Cyberspace and the Internet. London and New York: Routledge.

Wilhelm, 2000. Democracy in the Digital Age. New York: Routledge

Hershey PA-New York,39-55. Parlak,B \& Sobaci, Z. (2010). A Comparative analysis og Local agenda 21 websites in Turkey in terms of e-participation. 
Moreno, E. A., \& Traverso, D.B. (2010). E-Government and Citizen Participation in Chile: The Case of Ministries Websites. Christoper G. Reddick (Der), Politic, Democracy and E-Government: Participation and Service Delivery Icinde Information Science Reference, IGI Global.

Rheingold, Howard. (1995). Which Past is Virtual? Which Part is Community? / www.well.com/-hlr/tpmorrow/ vcreal.html 